\title{
Computed Tomographic Evaluation of Mediastinal Mass Lesions
}

\author{
S Satbeer Singh ${ }^{1}$, Sudhir Sachar ${ }^{2}$, Julius N. Toppo ${ }^{3}$, Anand Acharya ${ }^{4}$ \\ ${ }^{1}$ III Year Postgraduate, ${ }^{2}$ Professor and HOD, ${ }^{3}$ Professor, Department of Radiodiagnosis, Konaseema Institute of Medical \\ Sciences and Research, Foundation (KIMS \& RF), Amalapuram, ${ }^{4}$ Professor and Head, Department of Clinical Pharmacology, \\ Konaseema Institute of Medical Sciences and Research, Foundation (KIMS \& RF), Amalapuram, India
}

Corresponding author: Dr. Anand Acharya, MD, Professor and Head, Department of Clinical Pharmacology, Konaseema Institute of Medical Sciences and Research Foundation (KIMS \& RF), Amalapuram, India

DOI: http://dx.doi.org/10.21276/ijcmsr.2019.4.1.23

How to cite this article: S Satbeer Singh, Sudhir Sachar, Julius N. Toppo, Anand Acharya. Computed tomographic evaluation of mediastinal mass lesions. International Journal of Contemporary Medicine Surgery and Radiology. 2019;4(1):A94-A98.

\section{A B S T R A C T}

Introduction: The multitude of diseases affecting the mediastinum varies considerably, comprising of tumors (benign to extremely malignant), cysts, vascular anomalies, lymph node masses, mediastinitis, mediastinal fibrosis, and pneumomediastinum. Current research aimed to study the computed tomographic characteristics of Mediastinal mass lesions in Plain and Contrast-enhanced scans and to study the distribution of mediastinal masses and their extension to adjacent structures and compare the CT findings with pathological diagnosis wherever possible.

Materials and Methods: Present study was conducted on 50 cases in the age between two to seventy years for a period of 18 months (Nov 2016 to April 2018) in the Department of Radio-diagnosis, Konaseema Institute of Medical Sciences and Research Foundation, Amalapuram. Referred patients from Medicine, Surgery, and evaluated through detailed history, necessary physical examination and computed tomography are carried out using CT scan-GE 16slicescannerwithboth Plain and Contrast study.

Results: CT with a diagnostic accuracy of $94 \%$ is a highly usefulmodality for the investigation of mediastinal masses. Conclusion: CT plays a significant role in the assessment of various mediastinal pathology, regarding diagnosis, distribution pattern and mass effect on adjacent structures.

Keywords: Benign, Malignant, Mediastinum, International Thymic Malignancy Interest Group, Computed Tomography.

\section{INTRODUCTION}

Computed tomography is a new method of forming images from $x$-rays. It was developed and introduced into clinical use by the British physicist Godfrey Hounsfield ${ }^{2}$ in 1972. It has revolutionised the field of diagnostic radiology.

The term mediastinum is commonly applied to the region between the two pleural sacs bounded anteriorly by sternum and posteriorly by the thoracic vertebral column and extending from the thoracic to diaphragm. The International Thymic Malignancy Interest Group (ITMIG) has introduced a new definition of classification of mediastinal compartments (Fig 1) was developed to reflect a division of the mediastinum based on cross-sectional imaging ${ }^{1}$ includes prevascular (anterior), visceral (middle), and paravertebral (posterior) compartments.

The multitude of diseases affecting the mediastinum varies considerably, comprising of tumors (benign to extremely malignant), cysts, vascular anomalies, lymph node masses, mediastinitis, mediastinal fibrosis, and pneumomediastinum. CT clearly demonstrates the malleable nature of the cysts, which change their shape with respect to change in position from prone to decubitus. ${ }^{2}$
Various diseases used to effect mediastinum that includes cysts, tumors (both malignant and benign), vascular abnormalities, infection to mediastinum, fibrosis, lymph node enlargement and fibrosis. ${ }^{3}$ Malleable nature of cyst can be demonstrated by change in position; various criteria's were used to demonstrate the mediastinal invasion for example meeting of tumor with the mediastinum, angle between mass and mediastinum (more than $90^{\circ}$ ) main stem bronchus thickness at proximal end. ${ }^{4}$ CT finding is more accurate in correlation of clinical date. ${ }^{5} \mathrm{CT}$ scan can differentiate benign lesion from malignant lesions. It can differentiate between vascular or a vascular etiology of mediastinum widening. ${ }^{6}$ Enlargement of lymph node can be present in all compartments but it is commonly present in middle mediastinum. ${ }^{7}$

Current research aimed to study the computed tomographic characteristics of Mediastinal mass lesions in Plain and Contrast-enhanced scans and to study the distribution of mediastinal masses and their extension to adjacent structures and compare the CT findings with pathological diagnosis wherever possible

\section{MATERIAL AND METHODS}

All patients referred to Department of Radio-Diagnosis, 
Konaseema Institute of Medical Sciences and Research Foundation with clinically suspected mediastinal spaceoccupying lesions were taken up for the study between Nov 2016 to April 2018 with thorough clinical history and clinical examination done before CT examination.

\section{Inclusion criteria}

a. Clinically suspected cases of mediastinal mass

b. Chest $\mathrm{X}$-ray with mediastinum mass

\section{Exclusion criteria}

a. Traumatic causes

b. Cardiac Causes

\section{Technique}

Routine anteroposteriortomogram of the thorax was initially taken in all patients in the supine position with the breath held. An axial section of $10 \mathrm{~mm}$ thickness was taken from the level of a thoracic inlet to the level of supra renal.In all cases, a plains can was followed by contrast scan, intermittent suspended inspiration. For contrast enhancement initially
80-100 ml of dynamic injection of Diatrizoatemeglumine and Diatrizoatesodium (Trazograf 76\%; Urograffin 76\%, $60 \%)$ OR in a dose of $300 \mathrm{mg}$ of Iodine/ $\mathrm{Kg}$ body weight (in children) was given an axial section were taken from thoracic inlet to the level of suprarenal's. The scans were reviewed on a direct display console at multiple window settings i.e.soft tissue (mediastinal) window at 320/40; Lung window 1400/600 ; a Bone window of 2400/200 to examine the wide variety of tissue density and also to look for osseous involvement. The pre and post contrast at tenuation values, the size, location of the mass, presence of calcification, mass effect on adjoining structures and others associated findings were studied along with the panel of a radiologist.

\section{RESULTS}

In the study out of 50 cases, 30 cases $(60 \%)$ were males and 20 cases (40) were females. Of 50 cases, 14 cases (28\%) were children. Among them 8 were males (i.e57.2\%) and 6 were females (i.e.48.2\%).

\begin{tabular}{|c|c|c|c|c|c|c|}
\hline \multirow[t]{2}{*}{ Age in Years } & \multicolumn{2}{|c|}{ Male } & \multicolumn{2}{|c|}{ Female } & \multicolumn{2}{|c|}{ Total } \\
\hline & No of cases & Percentage & No of cases & Percentage & No of cases & Percentage \\
\hline & 8 & 57.2 & 6 & 42.8 & 14 & 28 \\
\hline $16-30$ & 3 & 37.5 & 5 & 62.5 & 8 & 16 \\
\hline $31-45$ & 4 & 57.2 & 3 & 42.8 & 7 & 14 \\
\hline $46-60$ & 11 & 73.3 & 4 & 26.7 & 15 & 30 \\
\hline$>61$ & 4 & 66.7 & 2 & 33.3 & 6 & 12 \\
\hline & 30 & 60 & 20 & 40 & 50 & \\
\hline
\end{tabular}

\begin{tabular}{|c|c|c|c|}
\hline Features & Compartment/lesions & No of Cases & Percentage \\
\hline \multirow[t]{3}{*}{ Frequency of masses } & Anterior Mediastinum & 26 & 52 \\
\hline & Middle Mediastinum & 9 & 18 \\
\hline & Posterior Mediastinum & 15 & 30 \\
\hline \multirow[t]{8}{*}{ Anterior Mediastinal Lesions distribution } & Thymic masses & 7 & 26.9 \\
\hline & Metastatic Lymph Node & 5 & 19.2 \\
\hline & TB LymphNode & 4 & 15.4 \\
\hline & Aortic Mass & 4 & 15.4 \\
\hline & Lymphoma & 3 & 11.6 \\
\hline & Thyroid Mass & 2 & 7.7 \\
\hline & Germ cell Tumour & 1 & 3.8 \\
\hline & & 26 & 100 \\
\hline \multirow[t]{6}{*}{ Middle mediastinal Lesions distribution } & Metastatic Lymph Node & 4 & 44.5 \\
\hline & TB Lymph Node & 2 & 22.2 \\
\hline & Neuroenteric cyst & 1 & 11.1 \\
\hline & Esophageal Duplication Cyst & 1 & 11.1 \\
\hline & Bronchogenic Cyst & 1 & 11.1 \\
\hline & & 9 & 100 \\
\hline \multirow[t]{7}{*}{ Posterior mediastinal masses distribution } & Neural tumors & 5 & 33.3 \\
\hline & Paravertebral abscess & 3 & 20 \\
\hline & TB Lymph Node & 2 & 13.3 \\
\hline & Oesophageal mass & 2 & 13.3 \\
\hline & Hydatid cyst & 1 & 6.7 \\
\hline & Paravertebral hematoma & 1 & 6.7 \\
\hline & Lymphangioma & 1 & 6.7 \\
\hline
\end{tabular}


The most common age group to present with the mediastinal mass was between 46-60yrs comprising of 15 cases constituting $30 \%$ of the total in which males (11 in number=

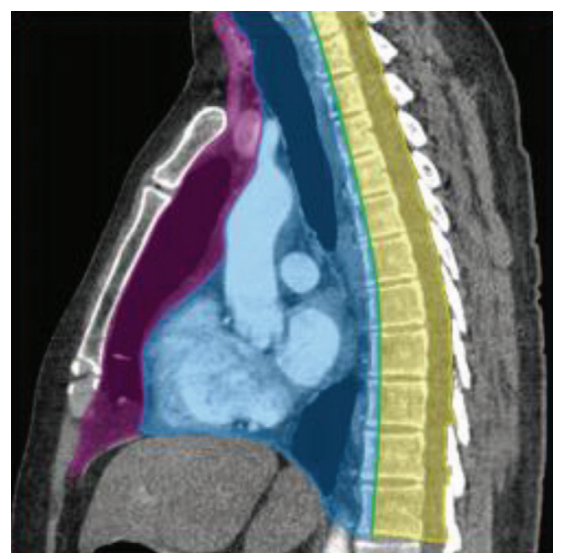

Figure-1: ITMIG definition of mediastinal compartments. Sagittal reformatted CT image shows a prevascular compartment (purple) wraps around the heart and pericardium, which are located in the visceral compartment (blue). Yellow = paravertebral compartment, Green line = visceral-paravertebral compartment boundary line.
$73.3 \%$ ) and females (4 in number $=26.7 \%$ ).

\section{Symptom}

In present study we have found that cough was the most common finding that is in $44 \%$ patients followed by Dyspnoea $38 \%$, fever $20 \%$ and chest pain $20 \%$. In the study out of 50 cases, 3 cases had no symptoms pertaining to the chest and CT showed incidental involvement of the mediastinum.

As per table -2 we have observed that anterior mediastinal mass is most common that is $52 \%$ of total mass.we have also found that thymic masses were commonly found in anterior mediastinum (26.9\%) followed by metastatic lymph node.In present study middle mediastinal mass was (18\%) of total masses. In middle mediastinum metastatic lymph node masses were most common that is $44.5 \%$ followed by tuberculosis lymph node enlargement that was $22.2 \%$ (Table 4).

Posterior mediastinum masses which compered of $30 \%$ of total masses, neural tumor are common in here that is $40 \%$. Para vertebral abscess is second most common, finding (table - 2 Thymoma is diagnosed $42.8 \%$. among all thymic masses. Common age group was 45 to 60 yrs and having male predominates. Thymic hyperplasia was common in young $(0-$ 15yrs) age patients.

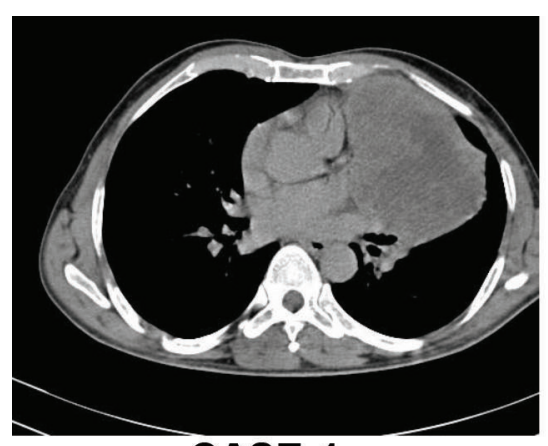

CASE-1

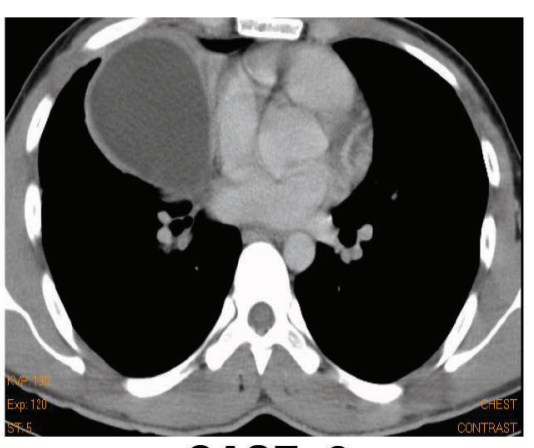

CASE- 2

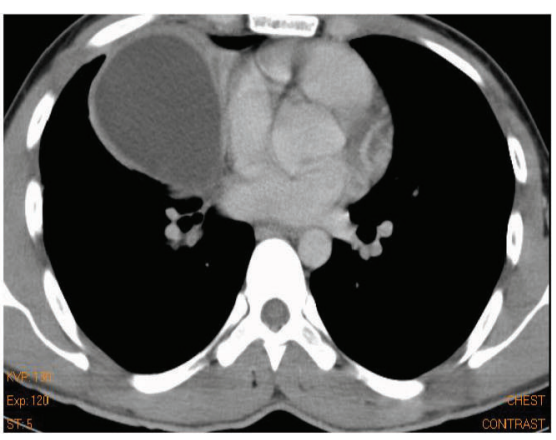

CASE- 3

Figure-2: Showing masses commonly found in various compartment

\begin{tabular}{|l|l|c|c|c|}
\hline & Mediastinal Masses & Total & Histological findings & Nonverifying \\
\hline 1. & Anterior Mediastinum & 26 & 21 & 5 \\
\hline 2. & Middle Mediastinum & 9 & 9 & 0 \\
\hline 3. & Posterior Mediastinum & 15 & 13 & 2 \\
\hline \multicolumn{2}{|r|}{ Table-3: Correlation between CT and Histopathology } \\
\hline
\end{tabular}

\begin{tabular}{|l|l|c|c|}
\hline Characteristics of lesion & & No. of cases & Percentage \\
\hline CT enhancement pattern of mediastinal masses & Heterogeneous Enhancement & 22 & 44 \\
\cline { 2 - 4 } & Homogenous Enhancement & 14 & 28 \\
\cline { 2 - 4 } & Non enhancing & 6 & 12 \\
\cline { 2 - 4 } & Rim enhancement & 5 & 10 \\
\cline { 2 - 4 } & Intense enhancement & 3 & 6 \\
\hline \multirow{4}{*}{ Distribution of the masses based on their nature } & Solid masses & 27 & 54 \\
\cline { 2 - 4 } & Solid +Cystic masses & 6 & 22 \\
\cline { 2 - 4 } & Cystic & 4 & 12 \\
\cline { 2 - 4 } & Vascular masses & 1 & 2 \\
\cline { 2 - 4 } & Fatty masses & 1 & 2 \\
\cline { 2 - 4 } & Fatty +Cystic +Solid & & 2 \\
\hline
\end{tabular}


In the study of 6 cases of neurogenic tumors, neurofibroma constituted 50\% ( $\mathrm{n}=3$ ), ganglioneuroblastoma16.6\% ( $\mathrm{n}=$ 1), schwannoma $16.6 \%(\mathrm{n}=1)$ and paraganglioma $16.6 \%$ (n $=1$ ).

In the study, lymph nodal masses constituted $40 \%(\mathrm{n}=20)$ of the total mediastinal masses. Among these the metastatic $\mathrm{LN}$ involvement is the predominant constitutes 39.1\% ( $\mathrm{n}=$ 9) followed by TB LN enlargement $34.8 \%(n=8)$.

In the study, all 43 cases are histologically verified and 4 cases of vascular origin aortic disorderare confirmed with conventional angiography. Remaini

In the study, majority of the masses, showed heterogeneous enhancement, i.e., 44\% ( $\mathrm{n}=22)$ followed by homogenous enhancement; 28\% ( $\mathrm{n}=14)$ non enhancing masses constituted $12(\mathrm{n}=6)$ (table-4).

In the study, the majority were solid masses constituting $54 \%$ $(n=27)$ of the cases followed by solid and cystic masses in $22 \%(n=11)$ of the cases. In the study, $24 \%(n=12)$ of the cases showed calcification in the mediastinum mass. Mass effect was noted in $62 \%$ of the cases and was predominantly noted on the airways.

\section{CASE-1 THYMOMA}

Axial plain and CECT chest mediastinal window showing heterogeneous enhancing left anterior mediastinal mass with few cystic areas within it (figure-2).

\section{CASE- 2 BRONCHOGENIC CYST}

Axial CECT chest mediastinal window showing right well defined cystic anterior mediastinal mass lesion anterior to right hilum with a thin enhancing wall (figure-2).

\section{CASE- 3 NEUROGENIC TUMOUR}

Axial plain and contrast CT chest mediastinal window showing well defined homogenous enhancing left posterior mediastinal mass lesion extending into left hemithorax (figure-2).

\section{DISCUSSION}

The following study was undertaken with the objectives of determining the diseases of the mediastinum and to correlate the CT findings with the histopathology reports whenever possible.

Majority of the symptoms were of non-specific nature like cough, chest pain, fever, dysphagia etc. These symptoms were mainly due to the mass effect from the mediastinal lesions and we $\mathrm{r}$ e dependent on the location of the mass. Anterior mediastinal masses mostly presented with a cough and dyspnoea probably due to tracheal compression. Middle mediastinal lesions presented with dysphagia due to either involvement of the esophagus or its compression.

In our study of 50 cases, the majority of the mediastinum masses were in the anterior mediastinum constituting $52 \%$ followed by posterior and middle mediastinal compartment. According to the study conducted by Strollo et al. ${ }^{8,9}$ in1997 where in anterior mediastinum constituted 50\% of the masses.

In the study, anterior mediastinal masses comprises predominantly of thymic lesions $26.9 \%$ and metastatic lymph node constituting $19.2 \%(\mathrm{n}=5)$ followed by ascending aortic aneurysm constituting $15.4 \%(n=4)$ which is similar to the study conducted byHarmeet Kaur et al. ${ }^{10}$

In the present study metastatic lymph node appears to be common middle mediastinal mass Which is not supported by the study H. Kaur et al (10) as per H.kaur et al study o esophaseal masses were more common in our study posterior mediastinal mass are present in 30\% patients, among that $33.3 \%$ were neuronal tumors which corroborates with the finding of H.kaur et al(10).

Majority of mediastinal masses $64 \%(n=32)$ are benign lesions and seen most commonly in the age group of 31-40 years and $36 \%(\mathrm{n}=18)$ of the mediastinal masses were malignant and seen most commonly in the age group of 51-60. Our study is in concordance with Karki S et al. ${ }^{11}$ who showed in a study of 27 cases with mediastinal lesions that $18(66.6 \%)$ cases were benign and seven (26\%) cases were malignant and two (7.4\%) cases were inconclusive.

In this study, all 43 cases are histologically verified and 4 cases of vascular origin aortic disorder are confirmed with conventional angiography. Remaining 3 cases i.e. Thymic Hyperplasia, Lymphangioma and Hydatid cyst are managed conservatively. Accordingto the study conducted by HarmeetKauret al. ${ }^{10}$ in 2014 out of 120 cases, 102 cases were histologically verified, 6 cases were a hiatal hernia which were confirmed with endoscopy. In remaining 12 cases of vascular origin, a definitive diagnosis was established requiring no further evaluation. Present study histopathology correlates with the above-given study.

In our study, Granuloma constituted $16 \%$, which is greater in comparison to Wychuliset al. ${ }^{12}$ study (i.e. 6.3\%) probably due to a higher prevalence of Tuberculosis in comparison to the western population.

In our study intrathoracic goiters represented $4 \%(n=2)$ of the mediastinal lesion which is in concordance with the studies of Khairy J et al. ${ }^{13}$ and Raffaelli $\mathrm{M}$ et al. ${ }^{14}$ which showed that the retrosternal goiters accounted for 3\%-12\% and 7\% of mediastinal masses respectively.

The CT scan chest is the single most important diagnostic modality while evaluating mediastinal masses except for the posterior mediastinal tumors of "Neurogenic origin" (where MRI may be useful)Strollo et al. ${ }^{8,9}$ Moreover, MRI scans are superior to CT in defining vascular involvement and in distinguishing recurrent tumor from radiation fibrosis. In addition to the accurate assessment of the nature of the mass (solid versus cystic), CT can also detect fat and calcium within the tumor mass. The relationship with the surrounding structures and the extent of invasion is also accurately assessed by the CT scan.

Fine needle aspiration cytology is considered an adequate evaluation and when done under the guidance of CT the results are very good. However, core biopsies are preferable whenever lymphoma or thymoma is suspected.

\section{CONCLUSION}

Conclude that computed tomography definitely has a major role to play in the evaluation of a mediastinal mass regarding the organ of origin, distribution pattern, and extent of the lesion, its density and mass effect upon adjacent structures. 


\section{REFERENCES}

1. Carter BW, Tomiyama N, Bhora FY et al. A modern definition of mediastinal compartments. J ThoracOncol 2014;9(9 suppl 2):S97-S101.

2. Pugatch RD, Faling LJ, Robins AH. Computerised Tomographic diagnosis of benign mediastinal abnormalities. AJR.1980; 134: 685. PMid: 6767352. http://dx.doi.org/10.2214/ajr.134.4.685

3. Redina A, Munden RF, Pugatch RD, Liptay MJ. Computerised Tomographic staging of anterior mediastinal neoplasms. Thorax. 1988; 43: 441-45.

4. Crowe JK, Brown LR, Muhm JR. Computed Tomography of the Mediastinum. Radiology. 1978; 128(3): 75-87.

5. Webb WR. Advances in computed tomography of the thorax.RadiolClin North Am. 1983; 21(4): 723-29. PMid: 6657967.

6. Baron RL, Levitt RG, Sagel SS, Stanley RJ. Computed tomography in the evaluation of mediastinal widening. Radiology.1981; 138(6): 107-13.

7. Naidich DP, Webb WR, Muller NL, Zerhouni EA, Seigelmann SS. Computed tomography and Magnetic Resonance of the thorax. 3rd ed. Philadelphia: Lippincott Williams and Wilkins. 1999; 38-160.

8. Strollo DC, Rosado de Christenson ML, JettJR. Primary mediastinal tumors. Part I. Tumors of the anterior mediastinum.Chest 1997; 112(5): 511-522.

9. Strollo DC, Rosado de Christenson ML, JettJR. Primary mediastinal tumors: Part II, Tumors of the middle and posterior mediastinum.Chest 1997; 112(1): 1344-57.

10. HarmeetKaur, PunitTiwari, Pankaj Dugg. Computed tomographic evaluation of mediastinal masses/lesions with contrast enhancement and correlation with pathological diagnosis. Journal of Biomedical Graphics and Computing, 2014, Vol. 4, No.3.

11. Karki S, Chalise S. Analysis of mediastinal lesions: a study of 27 cases. Journal of Pathology of Nepal. 2011; 1(6): 114-7.

12. Wychulis AR, Payne WS, Clagett OT et al.Surgical treatment of mediastinaltumours a 40 year experience. J Thorac Cardiovas Surg 1971; 62(4): 379-392.

13. Khairy G, Alsaif A. Large Retrosternal Goitre: A Diagnostic and Treatment Dilemma. OMG. 2010; 25(1): 44.

14. Raffaelli M, Bellantone R, Princi P. Surgical treatment of thyroid diseases in elderly patients. American Journal of Surgery. 2010; 200(4): 467-72.

Source of Support: Nil; Conflict of Interest: None

Submitted: 01-02-2019; Accepted: 02-03-2019; Published online: 20-03-2019 